\title{
Distribution and Fungicide Sensitivity of Fungal Pathogens Causing Anthracnose-like Lesions on Tomatoes Grown in Ohio
}

\author{
Laura J. Gutierrez Chapin, Ying Wang, Elizabeth Lutton, and Brian B. McSpadden Gardener, Department of \\ Plant Pathology, The Ohio State University, Ohio Agricultural Research and Development Center, Wooster 44691
}

\begin{abstract}
Gutierrez Chapin, L. J., Wang, Y., Lutton, E., and McSpadden Gardener, B. B. 2006. Distribution and fungicide sensitivity of fungal pathogens causing anthracnose-like lesions on tomatoes grown in Ohio. Plant Dis. 90:397-403.

The primary causal agents of anthracnose-like fruit rots in Ohio and their potential resistance to fungicides commonly used to control these fungal pathogens were determined. Nineteen tomato production fields throughout the state were sampled in 2002 and 2003 for fruit with anthracnoselike lesions. Fungi were isolated from these samples, classified using restriction fragment length polymorphism analysis, and identified by internal transcribed spacer sequence analysis. Some of the fungi isolated may represent secondary invaders of preexisting wounds or lesions. Colletotrichum spp. were most abundant in our collection, representing 136 of the 187 isolates. In addition, there were 23 Alternaria, 12 Fusarium, 12 Phomopsis, and 4 Mucor isolates. Colletotrichum, Alternaria, and Fusarium spp. were found throughout the major tomato production areas in the state. In a laboratory investigation, a subset of the Colletotrichum, Alternaria, and Fusarium isolates caused symptoms similar to early development of anthracnose on wounded tomato fruit. In vitro inhibition assays indicated that most Colletotrichum isolates were sensitive to labeled rates of azoxystrobin, chlorothalonil, and mancozeb. However, some Alternaria isolates were less sensitive to azoxystrobin and chlorothalonil than the Colletotrichum isolates. In addition, most Fusarium isolates were also more insensitive to azoxystrobin and mancozeb, and most Phomopsis isolates were not inhibited by azoxystrobin at the levels tested. The patterns of insensitivity to azoxystrobin and chlorothalonil were also observed in situ with excised fruit. Because the fungicides tested are not currently labeled for control of tomato diseases caused by Fusarium or Phomopsis, these results indicate that some pathogen species that can cause anthracnose-like symptoms may not be entirely sensitive to fungicides commonly used in tomato production.
\end{abstract}

Anthracnose is a major disease in a variety of crops including grains, fruits, vegetables, and ornamentals. The pathogens causing anthracnose are species of the genus Colletotrichum (10). Colletotrichum species can have multiple hosts, and likewise, hosts can be infected by various species (13). Disease can occur both above- and belowground and cause preand postharvest disease symptoms. These pathogens can cause serious economic losses, especially when fruit are infected, where up to $50 \%$ crop loss may occur (28).

Every year in Ohio, marketable yield of both processing and fresh-market tomatoes is reduced due to fruit rot. Anthracnose is thought to be the primary disease; however, there are several other tomato fruit rot diseases $(19,25)$. Fungal fruit rots cause

Corresponding author: B. B. McSpadden Gardener E-mail: bbmg+@osu.edu

Accepted for publication 24 October 2005.

DOI: 10.1094/PD-90-0397

(C) 2006 The American Phytopathological Society economic loss through the rejection of tomato shipments due to spore count past threshold at tomato processing plants, or the rejection of tomatoes by buyers and/or consumers due to visible lesions. C. coccodes can cause disease on green or red fruit under favorable conditions (9). The pathogen can cause latent infection, in that green fruit can be infected but asymptomatic with lesion development not occurring until fruit reach maturity or the plant begins to senesce $(6,17)$. The symptoms on red fruit are dark, sunken, circular lesions. As the disease progresses, black dots may be visible on the inner portion of the lesion. Additionally, orange ooze containing spores may exude from the lesion under high humidity.

Without proper management of anthracnose fruit rot, there can be up to $70 \%$ yield loss (6). Even in years when environmental conditions are favorable and chemical spray programs are followed accordingly, incidence of fruit rot can be up to 5 to $15 \%$ $(5,11)$. Azoxystrobin, chlorothalonil, fixed copper, and mancozeb are the fungicides most commonly used to control anthracnose fruit rot in Ohio (24). On average in
Ohio, there are $2.9,4.4,12.2$, and 12.9 applications of azoxystrobin, chlorothalonil, fixed copper, and mancozeb per year, averaging $1.4,38.9,50.1$, and 60.9 total pounds of active ingredient per year, respectively. Such large numbers of applications may lead to fungicide resistance $(26,29)$. However, no reports have been made of fungicide resistance in $C$. $c o c$ codes.

The objectives of this research were to identify pathogens causing symptoms resembling anthracnose fruit rot in Ohio tomato fields and to investigate the effectiveness of fungicides commonly used in tomato production against the isolated fungi using wounded and unwounded tomato fruit and in vitro inhibition assays with amended media.

\section{MATERIALS AND METHODS}

Isolate collection and maintenance. Sixteen fields in the following seven counties of Ohio were chosen for sampling of fruit with symptoms of anthracnose fruit rot during the summer 2002 field season: Fulton, Geauga, Huron, Meigs, Portage, Sandusky, and Wayne. The Fulton, Sandusky, and Wayne county fields were conventional processing tomato fields. The fields of Huron, Geauga, and Meigs counties were conventionally produced freshmarket tomato fields, and the Portage field was an organic fresh-market tomato field. In 2003, seven fields in five counties were sampled: Geauga, Meigs, Sandusky, Wayne, and Wood. Organic fresh-market tomato fields were located in Geauga, Meigs, and Sandusky counties. Conventionally produced fresh-market fields were located in Geauga and Meigs counties. Processing tomatoes under organic transition were sampled from a field in Wayne County. Conventionally produced processing tomatoes were sampled from fields in Sandusky and Wood counties.

Fruit were surface-sterilized in $10 \%$ bleach for approximately $5 \mathrm{~min}$. The fruit then were rinsed three times in sterile distilled water $\left(\mathrm{dH}_{2} \mathrm{O}\right)$. Using aseptic technique, a section of the lesion's leading edge was cut and removed from the fruit. The sample was plated on antibioticamended V8 juice agar (26\% V8 juice, calcium carbonate at $2.7 \mathrm{~g} / \mathrm{liter}$, and agar at $14 \mathrm{~g} /$ liter, amended with $0.1 \mathrm{~g} /$ liter each of 
chloramphenicol and streptomycin to inhibit bacterial growth). Petri dishes were sealed with Parafilm and incubated at room temperature $\left(20\right.$ to $22^{\circ} \mathrm{C}$ ) in the dark for a maximum of 4 days. Hyphal tips from fungal colonies were cut and transferred to fresh medium. Mycelia of pure isolates were stocked in $17 \%$ glycerol in $-80^{\circ} \mathrm{C}$ freezer for long-term storage.

DNA extraction and restriction fragment length polymorphism (RFLP) analysis. DNA was isolated from fungal mycelia grown on V8 juice agar using the UltraClean Soil DNA Kit (Mo Bio Laboratories Inc., Solana Beach, CA) according to the manufacturer's instructions. The internal transcribed spacer (ITS)-1 and ITS-2 regions of approximately $50 \mathrm{ng}$ of genomic DNA were amplified with universal primers ITS-4 (TCCTCCGCTTATTGATATGC) and ITS-5 (GGAAGTAAAAGTCGTAACAAGG). Amplifications were carried out in $25-\mu 1$ reaction mixtures containing $2.5 \mu \mathrm{l}$ of DNA template, $1 \times \mathrm{Taq}$ DNA polymerase buffer (Promega, Madison, WI), $1.8 \mathrm{mM} \mathrm{MgCl}_{2}$ (Promega), 200 $\mu \mathrm{M}$ each of dGTP, dATP, dCTP, and dTTP (Invitrogen, Carlsbad, CA), 50 pmol of each primer, and 1.5 units of Taq DNA polymerase (Promega). Amplifications were performed in a thermal cycler (PTC200 DNA Engine, MJ Research, Waltham, MA) with the following conditions: $5 \mathrm{~min}$ at $95^{\circ} \mathrm{C}, 31$ cycles of $1 \mathrm{~min}$ at $94^{\circ} \mathrm{C}, 45 \mathrm{~s}$ at $52^{\circ} \mathrm{C}$, and $2 \mathrm{~min}$ at $70^{\circ} \mathrm{C}$, and then an 8 min final extension at $70^{\circ} \mathrm{C}$, followed by $5^{\circ} \mathrm{C}$ soak and $-20^{\circ} \mathrm{C}$ storage. Polymerase chain reaction $(\mathrm{PCR})$ products $(6 \mu \mathrm{l})$ were separated by gel electrophoresis in $1.5 \%$ agarose gel in $0.5 \times$ Tris-borate-EDTA (TBE) at $125 \mathrm{~V}$ for $2.5 \mathrm{~h}$. Gels were stained in dilute ethidium bromide (1 mg/liter), visualized under UV light, photographed using the Kodak 1D LE 3.5 software (Kodak, New Haven, CT), and stored as jpg files with the Kodak DC290 digital imaging software (Kodak, Rochester, NY).

For RFLP analyses, $9 \mu$ of a PCR product was digested in a total volume of $15 \mu \mathrm{l}$ of NEBuffer 2 with 10 units of RsaI or MspI (New England BioLabs, Beverly, MA). Reactions were incubated for $3 \mathrm{~h}$ at $37^{\circ} \mathrm{C}$ and stored at $-20^{\circ} \mathrm{C}$. Products were separated on $2 \%$ agarose gels in $0.5 \times \mathrm{TBE}$ for $3 \mathrm{~h}$ at $125 \mathrm{~V}$. Gels were stained and images were taken as described above. Banding patterns were scored by comparison to a 100-bp DNA ladder (New England BioLabs).

Sequence analysis. ITS sequences were obtained from a subset of isolates representing each distinct ITS RFLP pattern in the collection. PCR products generated from ITS4/ITS5 primer set were purified using the QIAquick PCR Purification Kit (Qiagen Inc., Valencia, CA) according to the manufacturer's instructions. Purified PCR fragments were ligated into the pGemT-easy plasmid cloning vector at $4{ }^{\circ} \mathrm{C}$ overnight. Ligated DNA was transformed into competent cells (JM109). Transformed colonies were selected on LuriaBertani (LB) media amended with 80 $\mu \mathrm{g} / \mathrm{ml}$ Xgal (5-bromo-4-chloro-3-indolyl$\beta$-D-galactoside), $0.5 \mathrm{mM}$ IPTG (isopropyl- $\beta$-D-thiogalactopyranoside), and 100 $\mu \mathrm{g} / \mathrm{ml}$ ampicillin. Selected transformants were checked for full-length insertions by PCR as described above. All clones were sequenced in the forward direction by the use of the T7 forward primer. Genomic DNA was amplified with primers Sp6 (TACGATTTAGGTGACACTATAG) and T7 (GTAATACGACTCACTATA). Amplifications were carried out in $25-\mu \mathrm{l}$ reaction mixtures containing $1 \mu \mathrm{l}$ of whole cell template, $1 \times$ Taq DNA polymerase buffer (Promega), $3.0 \mathrm{mM} \mathrm{MgCl} 2,200 \mu \mathrm{M}$ each of dGTP, dATP, dCTP, and dTTP, 50 pmol of each primer, and 1.5 units Taq DNA polymerase. Amplifications were performed in a thermal cycler with the following cycling conditions: $9 \mathrm{~min}$ at $94^{\circ} \mathrm{C}, 35$ cycles of $1 \mathrm{~min}$ at $94^{\circ} \mathrm{C}, 45 \mathrm{~s}$ at $56^{\circ} \mathrm{C}$, and $2 \mathrm{~min}$ at $72^{\circ} \mathrm{C}$, and then a 7 -min final extension at $72^{\circ} \mathrm{C}$, followed by a $5^{\circ} \mathrm{C}$ soak and $-20^{\circ} \mathrm{C}$ storage. Samples were sent for sequencing to the Molecular and Cellular Imaging Center (Wooster, OH). PCR fragments were identified by comparing the unknown ITS-1 and ITS-2 sequences with known sequences in the NCBI GenBank database using BLASTN software (2).

Pathogenicity. Isolates were selected based on genotype and location where collected. Pathogenicity of the fungal isolates was initially determined using a modified form of the assay described by Batson and Roy (4). An agar plug containing mycelia was taken from each recovered isolate and placed in the middle of a fullstrength potato dextrose agar (PDA) plate and incubated at room temperature for 5 days. Sterile, cut broom straw (approximately $1 \mathrm{~mm}$ diameter, $5 \mathrm{~mm}$ long) was placed on the culture plate and was incubated at room temperature for 7 days. Conventional tomato fruit were obtained from a local grocery produce department. The fruit were washed in soapy water and surface-sterilized in $10 \%$ bleach for $5 \mathrm{~min}$ followed by a triple rinse in sterile distilled water and dried with sterile paper towels. Fruit were placed on a wire rack in a plastic bin, stem side down. An infested broom straw was inserted into a fruit's upper hemisphere. Noninfested sterile broom straw was used as a negative control. The point of inoculation was covered with Parafilm. Warm sterile water $(500 \mathrm{ml})$ was added to the bottom of each bin, and the lids were closed tightly to maintain high relative humidity. The temperature in the plastic bins was approximately $28^{\circ} \mathrm{C}$. The lesion diameter was recorded after 3 and 7 days. Isolates included in the punctureinitiated pathogenicity tests were the following: Colletotrichum isolates Ge 2, Wy
8, Ft 26, and Sa 24; Alternaria isolates $\mathrm{Mg}$ 23, Po 2, Hu 17, and Ft 16; Fusarium isolates $\mathrm{Ge} 1, \mathrm{Hu} 1, \mathrm{Mg} 1, \mathrm{Hu} 10$, and $\mathrm{Ft} 25$; and Phomopsis isolates $\mathrm{Mg} 7, \mathrm{Mg} 11$, and Po 1. This experiment was conducted three times with five replicates for each isolate.

Pathogenicity was also determined for select isolates by treating tomato fruit attached to plants grown in a greenhouse with spore suspensions without wounding the fruit (8). Alternaria isolate Po 2 was grown on potato sucrose agar under fluorescent light for $4 \mathrm{~h}$ followed by dark incubation at room temperature. A Fusarium isolate, Ft 25, was grown under continuous fluorescent light at room temperature on PDA. After 10 days incubation, culture plates were flooded with sterile distilled water and the suspension was filtered through two layers of cheesecloth to remove debris. Conidia concentration was measured using a hemacytometer and was diluted to $4 \times 10^{5}$ conidia per $\mathrm{ml}$ using sterile distilled water. Cherry tomato plants were placed in a mist chamber set to mist for 15-s intervals every $105 \mathrm{~s}$ for a total of $22 \mathrm{~h}$ under continuous light, after which they were moved to a greenhouse bench. The average air temperature in the mist chamber was $22^{\circ} \mathrm{C}$, and the duration of leaf wetness was $22.5 \mathrm{~h}$. Fruits were labeled with a permanent marker, and the point of inoculation was surrounded with petroleum jelly to prevent the spore suspension from rolling off the fruit surface. Ten microliters of the conidial suspension was dispensed onto the fruit. Control fruits were inoculated with $10 \mu \mathrm{l}$ of sterile distilled water. Each isolate was tested on three fruit on each of three plants. Plants were watered twice a day and grown under natural light during late September to early October. Lesion diameter and lesion description were evaluated after 3 weeks. This experiment was conducted twice.

Evaluation of fungicide sensitivity in vitro. The capacities of different fungicides to inhibit fungal growth were determined using amended media. The fungicides used were mancozeb (Dithane F-45, Dow AgroSciences, Indianapolis, IN), chlorothalonil (Bravo Ultrex, Syngenta, Wilmington, DE), copper hydroxide (Kocide 2000, Griffin, Valdosta, GA), and azoxystrobin (Quadris, Syngenta). Mancozeb-, chlorothalonil-, and fixed copperamended media contained $20 \mathrm{mg}$ of fungicide product per liter of medium, 60 $\mathrm{mg} / \mathrm{liter}$, and $180 \mathrm{mg} / \mathrm{liter}$. Azoxystrobinamended media contained $3.3 \mu$ l of product per liter, $9.9 \mu \mathrm{l} /$ liter, and $29.7 \mu \mathrm{l} /$ liter of medium. The rates tested were chosen to represent a range of concentrations that could be expected to occur on tomato fruit. The concentrations chosen assumed that each petri plate represented a single tomato fruit, there are $5.0 \times 10^{5}$ tomato fruits per acre, the fruit received $20 \%$ of the total amount of sprayed product on a per-area basis, and the amount of product present in 
the top $0.5 \mathrm{~mm}$ of the agar was equivalent to that adhering to the fruit surface following a chemical spray application. The in vitro test also assumes that mycelial growth from a transferred agar block is inhibited in a manner akin to which germination and infection are inhibited. Using these model assumptions and parameters, the rates tested corresponded to approximately $1 / 3 \times, 1 \times$, and $3 \times$ the labeled field application rates of $2.5 \mathrm{~kg} / \mathrm{ha}$ for Dithane, Bravo, and Kocide, and $410 \mathrm{ml} / \mathrm{ha}$ for Quadris. As a control, nonamended V8 juice medium was prepared.

Small agar cubes containing mycelia were transferred to a series of media plates that included one plate for each of the four fungicides at all four concentrations, i.e., $0,1 / 3 \times, 1 \times$, and $3 \times$. The plates were sealed with Parafilm and incubated at room temperature until the control plate without fungicide was 80 to $90 \%$ covered with fungal growth. At that point, four radial growth measurements were taken from the edge of the agar cube to the leading edge of mycelia growth for each plate in the series. Each isolate was replicated four times. Percent growth inhibition in response to each fungicide at varying concentrations was calculated with the control plate as a reference such that percent inhibition is $[1-$ (growth of the experimental/growth of the control)]*100. This experiment was conducted twice.

Evaluation of fungicide sensitivity in situ. Two isolates each of Colletotrichum, Alternaria, and Fusarium were tested with a range of azoxystrobin and chlorothalonil concentrations on excised tomato fruit. Fivefold dilution series, $0,1 / 125,1 / 25,1 / 5$,

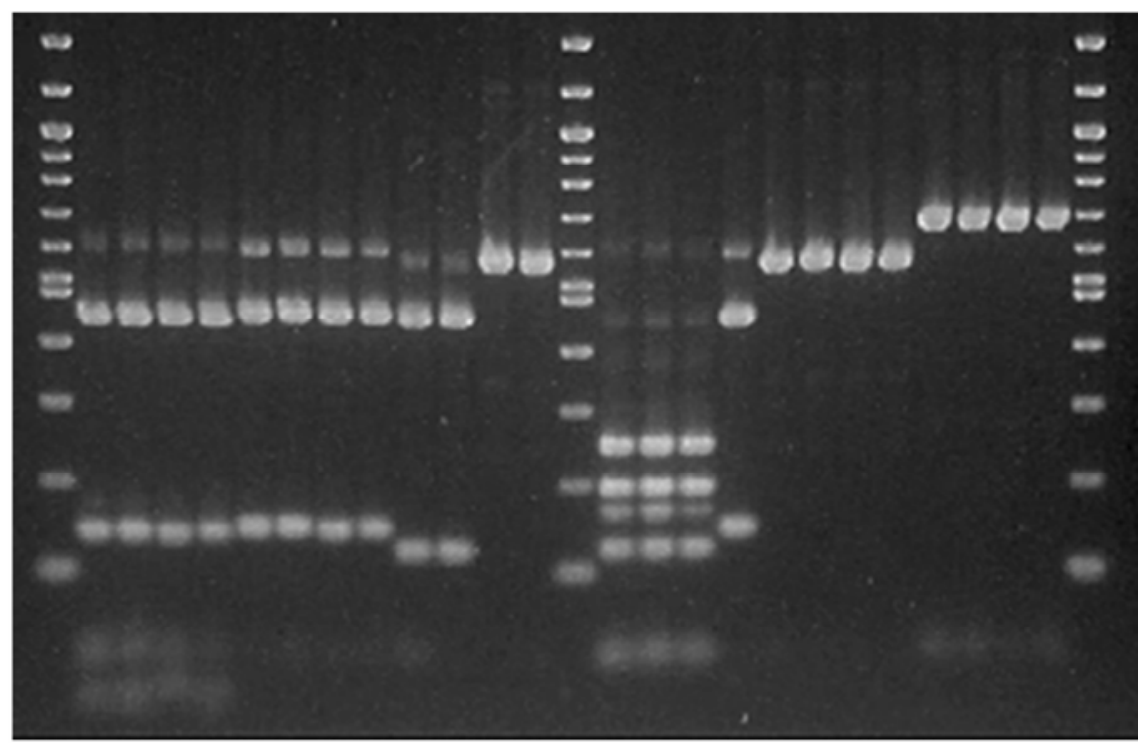

$\begin{array}{llllllllll}1 & 2 & 3 & 4 & 5 & 6 & 7 & 8 & 91011 & 12131415161718192021222324252627\end{array}$

Fig. 1. Determination of genotypes of fungal isolates from tomato fruit lesions by restriction fragment length polymorphism analysis of internal transcribed spacer region amplified with $M s p I$ restriction enzyme. Lane scheme is as follows: 100-bp ladder (lanes 1, 14, 27), genotype A (lanes 2 to 5), genotype B (lanes 6 to 9,18), genotype C (lanes 12,13, 19 to 22), genotype D (lanes 15 to 17), genotype E (lanes 10 and 11), and genotype $F$ (lanes 23 to 26). Isolates used in wound-inoculation assays were Wy 8 in lane 2, Mg 23 in lane 6, Po 2 in lane 8, Mg 1 in lane 12, and Ft 25 in lane 13. solve any additional genotypic variation. Of these, strains displaying genotype pattern A were most prevalent, representing $73 \%$ of the isolates. Genotype B represented nearly $15 \%$ of the isolates. The other genotypes represented fewer than $7 \%$ of the entire collection.

ITS sequence analysis was conducted on a subset of isolates to determine the genera of isolates obtained. Isolates from different locations with the same RFLP patterns were given preference for sequence analysis in order to investigate isolates from throughout Ohio. Sequence analysis revealed that each unique RFLP banding pattern corresponded to known sequences in GenBank. The genera identified were Colletotrichum, Alternaria, Fusarium, Phomopsis, and Mucor (Table 1). The ITS sequences yielding banding patterns $\mathrm{D}$ and E with MspI digest matched to Phomopsis. Some of the sequence analyses resulted in identity match greater than or equal to 99\% similarity (Table 1). In these instances, the following species were identified: Colletotrichum acutatum, C. dematium, C. coccodes, Fusarium culmorum, $F$. oxysporum, and F. sporotrichioides. The ITS DNA sequence of some isolates matching to Alternaria could not be identified to species, because multiple species share identical sequences that cannot be distinguished across the region analyzed (27). For example, the ITS sequence obtained from isolate $\mathrm{Mg} 23$ displaying pattern B was equally similar to Alternaria tenuissima, A. arborescens, A. infectoria, and $A$. alternata. The ITS sequence matching to Phomopsis had greater than or equal to $98 \%$ similarity but with no species designation according to Farr et al. (12).

Biogeography of genera. Colletotrichum was the most abundant genus observed in every county sampled (Table 2). The percentage of isolates identified as Colletotrichum spp. from six of the counties sampled ranged from 60 to $100 \%$. The major exception to this pattern was observed in Meigs County, where Alternaria and Phomopsis were the most frequently isolated fungi. Meigs County also had the largest diversity of genera isolated from tomato lesions, including isolates of all five genera detected in this study. Meigs County is also the only county from which isolates identified as being a species of the genus Mucor were isolated. Another potential exception to this pattern was observed in Portage County, where only three fungal isolates were collected, each of which was identified as a different genus.

Pathogenicity tests on excised and intact tomato fruit. The experiments in cluded assays that tested the stringent and lenient definitions of a pathogen. All genera were able to cause rot when inoculated into ripe, excised tomato fruit using infested broom straw to also wound the fruit (Fig. 2). Isolates of both Colletotrichum and Alternaria caused dark, sunken, circu- 
lar lesions, whereas Fusarium, Phomopsis, and Mucor isolates caused large sunken lesions and desiccation of the fruit tissue. In addition, Fusarium isolates grew out of the fruit tissue, producing white aerial mycelium. The Mucor isolate caused soft tissue rot. In addition to wound inoculation, spore suspensions of Fusarium isolate Ft 25 and Alternaria isolate Po 2 were capable of infecting unwounded intact cherry tomato fruit. Dark, soft tissue developed, similar to the early symptoms of anthracnose (Fig. 3).

In vitro fungicide sensitivity. Growth inhibition assays were used to determine the fungicide sensitivity of isolates within our collection. Significant differences in percent growth inhibition were observed among genera, but the patterns of relative sensitivity varied by compound (Table 3 ). Significant $(P<0.05)$ variation in sensitivity among genera was not detected for every concentration of each fungicide, but was highly significant overall for azoxystrobin, chlorothalonil, and mancozeb $(P$ $<0.005$ for all three fungicides).

Table 1. Identification of restriction fragment length polymorphism (RFLP)-defined fungal genotype based on ITS sequence

\begin{tabular}{|c|c|c|c|c|c|}
\hline Pattern $^{w}$ & County & Isolate & Identity match ${ }^{x}$ & Similarity $(\%)^{y}$ & DNA match ${ }^{z}$ \\
\hline A & Fulton & Ft 12 & Colletotrichum dematium & 98 & $545 / 556$ \\
\hline A & Fulton & Ft 26 & C. dematium & 99 & $570 / 573$ \\
\hline A & Huron & $\mathrm{Hu} 20$ & C. coccodes & 100 & $578 / 578$ \\
\hline A & Portage & Po 3 & C. acutatum & 100 & $533 / 533$ \\
\hline A & Portage & Po 4 & C. acutatum & 96 & $529 / 548$ \\
\hline A & Sandusky & Sa 3 & C. coccodes & 98 & $581 / 588$ \\
\hline $\mathrm{A}$ & Sandusky & $\mathrm{Sa} 23$ & C. coccodes & 99 & $460 / 462$ \\
\hline A & Wayne & Wy 8 & C. coccodes & 100 & $464 / 464$ \\
\hline B & Fulton & Ft 16 & Alternaria & 91 & $476 / 520$ \\
\hline B & Huron & $\mathrm{Hu} 5$ & Alternaria & 97 & $548 / 561$ \\
\hline B & Meigs & $\operatorname{Mg} 23$ & Alternaria & 98 & $551 / 561$ \\
\hline $\mathrm{C}$ & Fulton & $\mathrm{Ft} 25$ & Fusarium oxysporum & 99 & $533 / 534$ \\
\hline $\mathrm{C}$ & Geauga & Ge 1 & F. oxysporum & 96 & $303 / 314$ \\
\hline $\mathrm{C}$ & Huron & Hu 1 & F. oxysporum & 95 & $523 / 547$ \\
\hline $\mathrm{C}$ & Huron & $\mathrm{Hu} 10$ & F. oxysporum & 99 & $542 / 545$ \\
\hline $\mathrm{C}$ & Meigs & $\operatorname{Mg} 1$ & F. sporotrichioides & 98 & $506 / 516$ \\
\hline $\mathrm{C}$ & Meigs & $\operatorname{Mg} 10$ & F. culmorum & 99 & $552 / 556$ \\
\hline $\mathrm{D}$ & Meigs & $\operatorname{Mg} 7$ & Phomopsis & 99 & $557 / 558$ \\
\hline $\mathrm{D}$ & Meigs & $\operatorname{Mg} 8$ & Phomopsis & 98 & $594 / 603$ \\
\hline $\mathrm{D}$ & Meigs & $\operatorname{Mg} 11$ & Phomopsis & 98 & $591 / 603$ \\
\hline $\mathrm{E}$ & Portage & Po 1 & Phomopsis & 96 & $348 / 359$ \\
\hline $\mathrm{F}$ & Meigs & $\operatorname{Mg} 13$ & Mucor hiemalis & 94 & $114 / 124$ \\
\hline
\end{tabular}

${ }^{\mathrm{w}}$ Designation given to different restriction fragment length polymorphism patterns.

${ }^{x}$ Identity of organism whose sequence matched that of the isolate.

y Percent similarity of subject sequence to identified sequence in GenBank database.

${ }^{\mathrm{z}}$ Number of base pairs in subject sequence to number of base pairs in highest matched sequence.

Table 2. Percentage of isolates from various Ohio counties belonging to different genera identified through restriction fragment length polymorphism (RFLP) analysis

\begin{tabular}{lcccccc}
\hline & & \multicolumn{5}{c}{ Percentage of isolates } \\
\cline { 3 - 7 } County & $\mathbf{N}^{\mathbf{z}}$ & Colletotrichum & Alternaria & Fusarium & Phomopsis & Mucor \\
\hline Fulton & 26 & 92 & 4 & 4 & 0 & 0 \\
Geauga & 5 & 60 & 20 & 20 & 0 & 0 \\
Huron & 20 & 65 & 10 & 15 & 10 & 0 \\
Meigs & 40 & 12 & 38 & 17 & 23 & 10 \\
Portage & 3 & 33 & 33 & 0 & 33 & 0 \\
Sandusky & 49 & 98 & 2 & 0 & 0 & 0 \\
Wayne & 28 & 100 & 0 & 0 & 0 & 0 \\
Wood & 16 & 88 & 12 & 0 & 0 & 0 \\
\hline
\end{tabular}

${ }^{\mathrm{z}}$ Total number of isolates for a given RFLP genotype isolated from that county.
For chlorothalonil, Colletotrichum, Fusarium, and Phomopsis isolates were, on average, more sensitive than Alternaria isolates $(P=0.002$, Table 3$)$. Among the Colletotrichum isolates, there was a slightly lower degree of growth inhibition at the $1 \times$ concentration than noted for azoxystrobin $(47.1 \%$ versus $51.8 \%$ on average), but only one isolate, Ge 2 , displayed $<36 \%$ growth inhibition at the $3 x$ rate of chlorothalonil. The same three $\mathrm{Al}$ ternaria isolates ( $\mathrm{Hu} 5, \mathrm{Mg} \mathrm{23}$, and $\mathrm{Po} 2)$ that showed sensitivity to azoxystrobin were also relatively insensitive to chlorothalonil, showing $<35 \%$ growth inhibition at the $1 \times$ and $3 \times$ rates. The Fusarium isolates were relatively sensitive, with only Mg 1 being different and showing $<30 \%$ inhibition at the $1 \times$ level. Po 1 was also noted for its sensitivity to chlorothalonil $(<33 \%$ inhibition at $1 \times$ and $3 \times$ levels) relative to the other Phomopsis strains tested.

The four genera also differed in their sensitivity to mancozeb. Overall, Phomopsis isolates were significantly more inhibited by mancozeb than the Alternaria and Fusarium isolates $(P<0.001$, Table 3$)$. Colletotrichum isolates displayed similar sensitivity to that of Phomopsis, but were only significantly different from Fusarium at the $3 \times$ rate. Mancozeb was generally more inhibitory to Colletotrichum, Alternaria, and Phomopsis isolates than any other fungicide tested with 61,48 , and $88 \%$ growth inhibition, respectively, at the $1 \times$ rate. In contrast, five of the six Fusarium isolates tested were relatively insensitive, displaying $<27 \%$ and $<43 \%$ inhibition at the $1 \times$ and $3 \times$ rates, respectively.

Addition of fixed copper to the media resulted in only very limited growth inhibition of the fungi. Only one isolate, Phomopsis Po 8 , was inhibited by more than $20 \%$ at the $1 \times$ rate. There was significant $(P<0.044)$ variation among genera at the $3 \times$ concentration, with the Fusarium isolates not showing any growth inhibition. However, the average growth inhibition for the other three genera was never above $20 \%$.

In situ fungicide sensitivity of isolates. In situ fungicide sensitivity assays were conducted to further test the ability of azoxystrobin and chlorothalonil to inhibit lesion development on ripe fruit. In general, significant dose responses were observed in most of the in situ assays conducted with azoxystrobin. The doses at which Colletotrichum isolates Ft 26 and Wy 8 showed 50\% reduction in lesion size were $0.64 \times$. The only other fungus showing at least $50 \%$ reduction in lesion size in these assays was Alternaria strain Po 2, at the $5 \times$ concentration. For the other three fungi tested, lesion development was not significantly inhibited across the range of concentrations tested. Indeed, lesions developing from infections by the two Fusarium isolates, $\mathrm{Mg} 1$ and $\mathrm{Ft} 25$, and the 
other Alternaria isolate, $\mathrm{Mg}$ 23, were not inhibited by more than $25 \%$ even at the $5 x$ rate.

Interestingly, the chlorothalonil treatment was not capable of reducing lesion development by $50 \%$ for any of the isolates tested. And only Colletotrichum isolate Wy 8 and Alternaria isolate Po 2 responded to increasing chlorothalonil concentration with reduction in lesion size, resulting in a linear regression that deviated significantly from zero $(P=0.05)$. For each genus, lesion development was greatest for those isolates with the lowest fungicide sensitivity ratings in the in vitro assays. Indeed, Colletotrichum Wy 8, Alternaria $\mathrm{Mg}$ 23, and Fusarium $\mathrm{Mg} 1$ gave rise to lesions that were between 10 and 25\% larger than Colletotrichum Ft 26, Alternaria Po 2, and Fusarium Ft 25, respectively.

\section{DISCUSSION}

In this investigation, processing and fresh-market tomatoes were sampled from conventional and organic fields located in those Ohio counties with the greatest volume of tomato production (24). The majority of fungi isolated from tomatoes displaying anthracnose-like lesions were species of Colletotrichum. Sequence analysis revealed that $25 \%$ of the Colletotrichum isolates examined were actually $C$. acutatum, another $25 \% \mathrm{C}$. dematium, and remaining $50 \%$ were $C$. coccodes. Different species of Colletotrichum have been shown to cause fruit rot on tomato $(3,4,16,25)$. However, the sources of Colletotrichum and Glomerella in the 1982 study (4) included tomato and apple fruit lesions and a variety of hosts with foliar lesions, including weeds, grain crops, vegetables, and fruit. In our investigation, fungal isolates were collected from diseased tomato fruit found in processing or fresh-market tomato fields in Ohio. This survey allowed for the focus on fungal pathogens causing anthracnose-like symptoms in Ohio fields. The isolates collected in the current study could have been primary or secondary invaders. The isolates tested were capable of causing anthracnose-like symptoms on wounded or unwounded tomato fruit (Figs. 2 and 3). When testing the ability of spore suspensions of these isolates on greenhousegrown tomato fruit in a laboratory setting, all could infect tissue and cause lesions characteristic of Colletotrichum (data not shown). Virulence of all isolates was not determined.

Morpho-taxonomic criteria are commonly used to identify Colletotrichum spp. $(28,30)$. These criteria include shape and size of conidia, morphology and size of appressorium and setae, and response to temperature on PDA media. The analysis of restriction polymorphisms in amplified DNA regions is commonly used in the classification of many groups of microor- ganisms (31). Random amplified polymorphic DNA (RAPD) polymorphisms and ITS sequence analysis have been used to investigate genetic variation within Colletotrichum from strawberry (7). In addition, ITS region species-specific primers have been used to differentiate Colletotrichum species (21). In this investigation, the use of ITS sequence analysis paired with RFLP pattern analysis was useful in the identification of fungal isolates. We examined the morphology of spores from representative isolates for which ITS sequences were obtained (data not shown). Those observations were concordant with the ITS sequence-based identifications. The use of morphological characterization for the identification of such a large fungal collection could be a time-consuming and difficult task for the untrained eye. With the RFLP analysis, the collection of 187 isolates was readily classified into six groups. This enabled sequence analysis of only those isolates with unique banding patterns. Sequence analyses of amplified products indicated high levels of sequence identity with five different genera. Interestingly, the isolates identified as Phomopsis were associated with two different RFLP banding patterns. Additional digests of the amplified products failed to resolve any additional diversity in the other ribotypes (data not shown). Thus, our approach provides a rapid way to classify tomato fruit rot pathogens to the genus level.

Nearly $30 \%$ of the isolates obtained from anthracnose-like lesions were not Colletotrichum. Most of our nonColletotrichum isolates belong to genera previously associated with disease development on tomato (19). For example, A. alternata is the causal agent of black shoulder, which causes sunken black lesions. A. solani, the causal agent of early blight, causes black leathery sunken lesions when it infects fruit. However, $F$. oxysporum, the causal agent of Fusarium wilt, is not commonly associated with fruit infection. In our studies, isolates belonging to these genera were capable of causing lesions that mimic the early stages of anthracnose. It was interesting to find Alternaria spp. relatively frequently in our collection (23 of 187 isolates), because Alternaria has not been reported to be a major fruit rot pathogen in Ohio. In California, Alternaria is the most devastating tomato fruit rot pathogen (23). It is important to consider these non-Colletotrichum pathogens when implementing disease

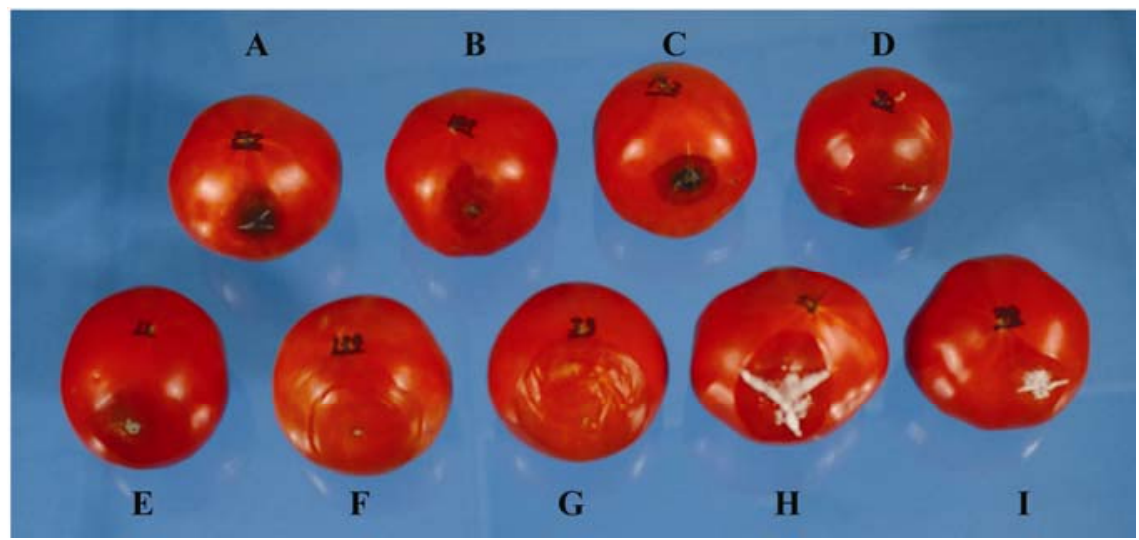

Fig. 2. Representative lesions characteristic of each of the representative genera, Colletotrichum (B and C), Alternaria (A and E), Fusarium (H and I), Phomopsis (D and F), and Mucor (G) on woundinoculated, detached fruit.

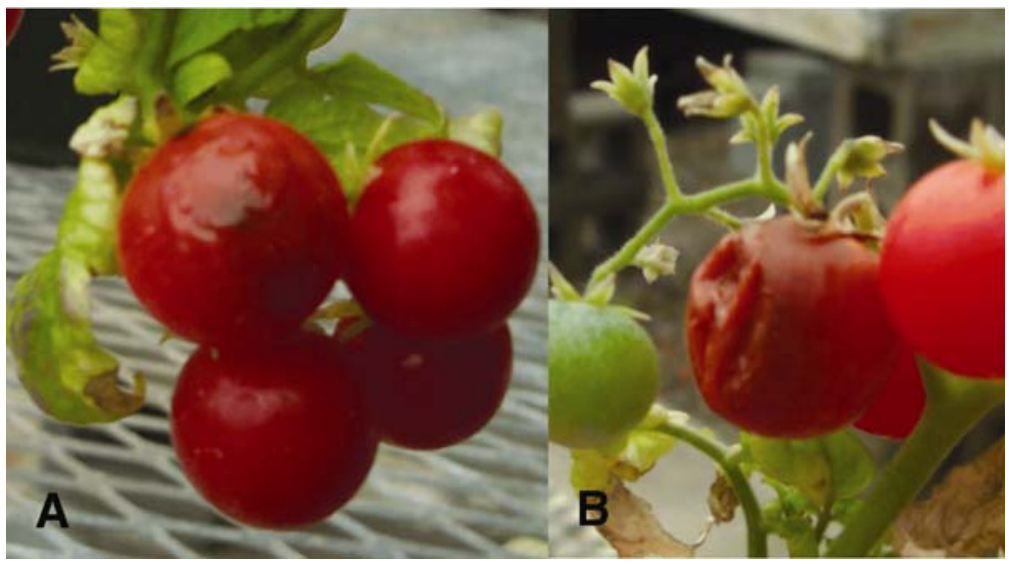

Fig. 3. Representative lesions that developed from Alternaria (A) and Fusarium (B) spore suspension inoculation onto intact cherry tomato fruit. 
control strategies. Continued reliance on azoxystrobin and chlorothalonil might favor these minor pathogens that are less sensitive to these fungicides than Colletotrichum such that they may become a larger problem in the future.

It is possible that the nonColletotrichum isolates may represent secondary infections from which the initial lesion-forming agent was displaced or outgrown during isolation. It is well known that Fusarium is fast growing and commonly isolated from soils and plant tissue. However, the ability of the Fusarium and Alternaria isolates to cause fruit rot symptoms similar to those found on the fruit from which they were isolated indicates that they are, at the very least, likely to be contributing agents to the fruit rots in the field. In contrast, the less frequently isolated Phomopsis and Mucor species isolated have not been previously associated with tomato disease. However, Mucor is also a common soilborne fungus that has been associated with postharvest fruit rot (1). Since these isolates did not cause anthracnose-like lesions, they are more likely secondary invaders or contaminants.

The percentage of total isolates per county belonging to each genus allowed for a comprehensive look at the distribution of fruit rot pathogens in Ohio. For each county sampled, the highest percentage of isolates was identified as Colletotrichum. Only three heirloom tomato fruit with typical anthracnose fruit rot symptoms were found at the time of sampling at a small certified organic farm in Portage County. Fungi isolated were Alternaria, Phomopsis, and Colletotrichum. In Meigs County, Alternaria was the most commonly isolated pathogen. In addition, the greatest diversity of genera was found in fields in this county. All of the tomato production in Meigs County is for the fresh market, and some growers in this county tend to plant tomatoes year after year in the same field. Tomato crops grown in this county would likely benefit from the use of rotations to reduce pathogen inoculum levels since it is well known that the pathogens observed in this study can overwinter for many years in soil and on crop debris (11). In addition, Meigs County is located in southeastern Ohio on the Ohio River, where environmental con- ditions may favor greater severity of fruit rots.

One goal of this work was to determine if the pathogens that cause anthracnoselike symptoms were sensitive to those chemicals commonly used in tomato disease control programs. Because tomato growers need to control a variety of diseases, they will use fungicide spray programs that include a variety of products. In Ohio, azoxystrobin, chlorothalonil, fixed copper, and mancozeb are all commonly used. These compounds are currently labeled for control of anthracnose in tomato, assuming it is caused by $C$. coccodes. Thus, the identification of other pathogens causing anthracnose-like lesions is significant, particularly since the isolates of these other genera appear to be more insensitive to products used to control anthracnose. In this regard, it is worth noting that none of the fungicides tested here have been labeled for the control of tomato diseases caused by Fusarium or Phomopsis spp., and only mancozeb and copper are currently labeled for the control of diseases caused by any species of these two genera in one or more other crops. With regard to azoxystrobin, the Colletotrichum isolates were more responsive to increasing concentrations in situ than the Alternaria and Fusarium isolates. This indicated a peculiar level of tolerance of the latter genera to azoxystrobin at the levels tested. Resistance to fungicides has been indicated in various pathosystems, and the modes of resistance have been investigated (14). The indicated lack of dose response to azoxystrobin and chlorothalonil may prove to be a major issue in tomato production if pathogens are becoming resistant to these two fungicides, since they are commonly used in spray programs for the control of various fruit rots. However, further work will be required to determine if the lack of dose response seen in our in vitro assays also occurs in spray trials using the labeled rates of the fungicides.

Fixed copper fungicides are commonly used to control bacterial diseases in tomato production; however, they are also labeled for the control of several fungal diseases on tomato. Our in vitro investigation indicated that the presence of fixed copper did not inhibit mycelia growth of any of the tested fungal isolates. This is consistent with previous work showing that copper application alone does not significantly reduce the number of fruit with anthracnose (20); however, we cannot assert that true resistance to copper fungicides occurs, because the amount of free copper ion available in our in vitro assays was not evaluated. The amounts of copper added cannot be equated to the amounts available for uptake by pathogens following a typical spray program. In fact, the amount of free copper present in our assay plates may be only a small fraction of that introduced because the $\mathrm{pH}$ of the media was approximately neutral (data not shown), a condition that prevents the release of free copper ion from its salt.

It is vital that growers use good management practices to control diseases in their fields through the integration of cultural, biological, and chemical control measures (18). The low tolerance of buyers to anthracnose symptoms, in both the processing and fresh-market industry, encourages growers to use the most effective disease control measures available. Integration of controlling soil-surface residue, implementing conservation tillage, and reducing fungicide application effectively managed tomato fruit rot and foliar blight such that marketable yield was not reduced (22). One management practice that aids in the prevention of resistance to fungicides is alternating use of chemicals with different modes of action (29). The use of weather-based forecasting systems is another tool to reduce application while maintaining desired yields, rather than calendar-based programs. These systems, such as TOM-CAST, have varied in effectiveness against anthracnose fruit rot depending on location in the United States $(11,15)$. In addition, this model was based on the epidemiology of $A$. solani. It was not optimized for recognizing the environmental conditions favorable for anthracnose disease in the Midwest (5). Therefore, farms plagued by anthracnoselike fruit rots caused by the different types of fungi found in this investigation may not benefit from use of an uncalibrated TOM-CAST system.

This investigation characterized the identification of fungal pathogens capable of causing anthracnose-like lesions and characterizing the sensitivity levels of

Table 3. Average percent growth inhibition of each genus by in vitro treatment with fungicides

\begin{tabular}{|c|c|c|c|c|c|c|c|c|c|c|c|c|c|}
\hline \multirow[b]{2}{*}{ Genera } & \multirow[b]{2}{*}{$\mathbf{N}^{\mathbf{x}}$} & \multicolumn{4}{|c|}{ Azoxystrobin } & \multicolumn{4}{|c|}{ Chlorothalonil } & \multicolumn{4}{|c|}{ Mancozeb } \\
\hline & & $0.3 x$ & $1 \times$ & $3 x$ & Ally & $0.3 \times$ & $1 x$ & $3 x$ & Ally & $0.3 \times$ & $1 x$ & $3 x$ & Ally \\
\hline Colletotrichum & 10 & $44 \mathrm{a}$ & $52 \mathrm{a}$ & $52 \mathrm{a}$ & A & $32 \mathrm{ab}$ & $47 \mathrm{a}$ & $70 \mathrm{a}$ & $\mathrm{AB}$ & $29 \mathrm{a}$ & $61 \mathrm{ab}$ & $84 \mathrm{a}$ & $\mathrm{AB}$ \\
\hline Alternaria & 7 & $26 \mathrm{a}$ & $37 \mathrm{a}$ & $46 \mathrm{ab}$ & $\mathrm{AB}$ & $17 \mathrm{~b}$ & $32 \mathrm{a}$ & $42 \mathrm{a}$ & $\mathrm{B}$ & $21 \mathrm{a}$ & $48 \mathrm{~b}$ & $73 \mathrm{ab}$ & B \\
\hline Fusarium & 6 & $25 \mathrm{a}$ & $33 a$ & $30 \mathrm{~b}$ & $\mathrm{~B}$ & $40 \mathrm{a}$ & $55 \mathrm{a}$ & $62 \mathrm{a}$ & A & $15 \mathrm{a}$ & $29 \mathrm{~b}$ & $43 \mathrm{~b}$ & B \\
\hline Phomopsis & 4 & $28 \mathrm{a}$ & $37 \mathrm{a}$ & $29 \mathrm{ab}$ & B & $49 \mathrm{a}$ & $67 \mathrm{a}$ & $71 \mathrm{a}$ & A & $33 \mathrm{a}$ & $88 \mathrm{a}$ & $100 \mathrm{a}$ & A \\
\hline$P$ value $\mathrm{z}$ & & 0.098 & 0.100 & 0.023 & 0.005 & 0.012 & 0.041 & 0.072 & 0.002 & 0.082 & 0.001 & $<0.001$ & $<0.001$ \\
\hline
\end{tabular}

$\mathrm{x}$ Total number of isolates included in the assay for each genus.

y Significant differences of the grand means were evaluated across all fungicide concentrations using Dunn's pairwise comparisons test and are indicated by different letters.

z The $P$ values presented were obtained from Kruskal-Wallis analysis of variance test. 
these pathogens to fungicide treatments. The levels of laboratory sensitivity observed do not necessarily reflect small degrees of field resistance. However, these findings represent strong rationale to investigate further the response of all fungal fruit rotting pathogens to commonly used fungicides in field studies. The current fungicide applications used in Ohio and the societal concerns about fungicide residues in food products and the environment indicate the need to study further the effectiveness of these chemicals against pathogens found in Ohio tomato fields.

\section{ACKNOWLEDGMENTS}

This publication was financed in part through a grant from the Ohio Department of Agriculture, the State of Ohio, and the U.S. Department of Agriculture under the provisions of the Specialty Crop Grant. This work was also supported by The Ohio State University - Ohio Agricultural Research and Development Center and the Ohio Vegetable and Small Fruit Research and Development Program.

\section{LITERATURE CITED}

1. Alexopoulos, C. J., Mims, C. W., and Blackwell, M. 1996. Introductory Mycology. John Wiley \& Sons, New York.

2. Altschul, S. F., Madden, T. L., Schaffer, A. A., Zhang, J., Zhang, Z., Miller, W., and Lipman, D. J. 1997. Gapped BLAST and PSI-BLAST: A new generation of protein database search programs. Nucleic Acids Res. 25:3389-3402.

3. Barksdale, T. H. 1972. Resistance in tomato to six anthracnose fungi. Phytopathology 62:660663.

4. Batson, W. E., and Roy, K. W. 1982. Species of Colletotrichum and Glomerella pathogenic to tomato fruit. Plant Dis. 66:1153-1155.

5. Byrne, J. M., Hausbeck, M. K., and Latin, R. X. 1997. Efficacy and economics of management strategies to control anthracnose fruit rot in processing tomatoes in the Midwest. Plant Dis. 81:1167-1172

6. Byrne, J. M., Hausbeck, M. K., Meloche, C., and Jarosz, A. M. 1998. Influence of dew period and temperature on foliar infection of greenhouse-grown tomato by Colletotrichum coccodes. Plant Dis. 82:639-641.
7. Denoyes-Rothan, B., Guerin, G., Delye, C., Smith, B., Minz, D., Maymon, M., and Freeman, S. 2003. Genetic diversity and pathogenic variability among isolates of Colletotrichum species from strawberry. Phytopathology 93:219-228.

8. Dhingra, O. D., and Sinclair, J. B. 1995. Cultivation and sporulation of some pathogens. Pages 17-44 in: Basic Plant Pathology Methods, 2nd ed. CRC Press, Boca Raton, FL.

9. Dillard, H. R. 1989. Effect of temperature, wetness duration, and inoculum density on infection and lesion development of Colletotrichum coccodes on tomato fruit. Phytopathology 79:1063-1066.

10. Dillard, H. R. 1992. Colletotrichum coccodes: The pathogen and its hosts. Pages 225-236 in: Colletotrichum: Biology, Pathology, and Control. J. A. Bailey and M. J. Jeger, eds. CAB International, Wallingford, UK.

11. Dillard, H. R., and Cobb, A. C. 1997. Disease progress of black dot on tomato roots and reduction in incidence with foliar applied fungicides. Plant Dis. 81:1439-1442.

12. Farr, D. F., Castlebury, L. A., and PardoSchultheiss, R. A. 1999. Phomopsis amygdali causes peach shoot blight of cultivated peach trees in the southeastern United States. Mycologia 91:1008-1015.

13. Freeman, S., Katan, T., and Shabi, E. 1998. Characterization of Colletotrichum species responsible for anthracnose diseases of various fruits. Plant Dis. 82:596-605.

14. Gisi, U., Chin, K. M., Knapora, G., Faber, R. K., Mohr, U., Sierotzki, H., and Steinfield, U. 2000. Recent developments in elucidating modes of resistance to phenylamide, DMI, and strobilurin fungicides. Crop Prot. 19:863-872.

15. Gleason, M. L., MacNab, A. A., Pitblado, R. E., Ricker, M. D., East, D. A., and Lain, R. X. 1995. Disease warning systems for processing tomatoes in eastern North America: Are we there yet? Plant Dis. 79:113-119.

16. Gourley, C. O. 1966. The pathogenicity of Colletotrichum dematium to table beets and other hosts. Can. J. Plant Sci. 46:531-536.

17. Illman, W. I., Ludwig, R. A., and Farmer, J. 1959. Anthracnose of canning tomatoes in Ontario. Can. J. Bot. 37:1237-1246.

18. Jacobsen, B. J. 1993. Biological and cultural plant disease controls: Alternatives and supplements to chemicals in IPM systems. Plant Dis. 77:311-315.
19. Jones, J. B., Stall, R. E., and Zitter, T. A. 1991 Compendium of Tomato Diseases. American Phytopathological Society, St. Paul, MN.

20. Lewis Ivey, M. L., Mera, J., and Miller, S. A. 2002. Evaluation of fungicides for the control of foliar and fruit diseases of processing tomatoes, 2002. Report 58:V064. DOI:10.1094/ FN57. American Phytopathological Society, St. Paul, MN.

21. Lewis Ivey, M. L., Nava-Diaz, C., and Miller, S. A. 2004. Identification and management of Colletotrichum acutatum on immature bell peppers. Plant Dis. 88:1198-1204.

22. Louws, F. J., Hausbeck, M. K., Kelly, J. F., and Stephens, C. T. 1996. Impact of reduced fungicide and tillage on foliar blight, fruit rot, and yield of processing tomatoes. Plant Dis. 80:1251-1256.

23. Morris, P. F., Connolly, M. S., and St. Clair, D. A. 2000. Genetic diversity of Alternaria alternata isolated from tomato in California assessed using RAPDs. Mycol. Res. 104:286292.

24. National Agricultural Statistics Service, U.S. Department of Agriculture. Ohio Agricultural Statistics Service. Online publication.

25. Prusky, D., Freeman, S., and Dickman, M. B 2000. Colletotrichum: Host specificity, pathology, and host-pathogen interaction. American Phytopathological Society, St. Paul, MN.

26. Russell, P. E. 1995. Fungicide resistance: Occurrence and management. J. Agric. Sci 124:317-323.

27. Serdani, M., Kang, J. C., Andersen, B., and Crous, P. W. 2002. Characterisation of Alternaria species-groups associated with core rot of apples in South Africa. Mycol. Res. 106:561-569.

28. Smith, B. J., and Black, L. L. 1990. Morphological, cultural, and pathogenic variation among Colletotrichum species from strawberry. Plant Dis. 74:69-76.

29. Staub, T. 1991. Fungicide resistance: Practical experience with antiresistance strategies and the role of integrated use. Annu. Rev. Phytopathol. 29:421-442

30. Tu, J. C., and Poysa, V. 1997. The diversity and overwintering of Colletotrichum coccodes in tomato fields in southwestern Ontario. Microbios 91:153-163.

31. Viaud, M., Psaquier, A., and Brygoo, Y. 2000. Diversity of soil fungi studied by PCR-RFLP of ITS. Mycol. Res. 104:1027-1032. 